Book Review:

\title{
Beggar Girls Of Karachi: A Survey
}

\author{
Muhammad Nadeemullah \\ Research Associate \\ Department of Social Work \\ University of Karachi
}

Dr. Nasreen Aslam Shah, Professor Department of Social Work and Director Women's Studies Centre, University of Karachi has diligently and meticulously composed "Beggar Girls of Karachi: A Survey". Along with her Shagufta Nasreen, Asma Manzoor, Aliyah Ali, Saba Parveen and Muhammad Nadeemullah worked as field survey team. They interviewed these girls and assisted in the research work. This book is an important piece of work as the topic is not only unique but meaningful also. It reflects a painful issue of our society and criticizes the claims of International, National and Non Governmental Organizations who are working for child rights. The research book contains approximately 150 pages, published in collaboration with Higher Education Commission (HEC) and printed by Department of Bureau of Composition Completion \& Translation (B.C.C \& T) University of Karachi. Children begging on streets, roads, bus stops, stations, tombs, sanctuaries, parks and recreational places are not only an important social problem of Pakistan but also of the developing countries. These children are facing a very dangerous problem, which is their sexual abuse. Especially the beggar girls are more prone to sexual exploitation and abuse. The issue of child sexual abuse of these girls is a moral challenge for all the governments and it needs to be analyzed by International organizations and NGOs. Analysis of this problem especially in third world context shows that both the number of beggar girls and the ratio of sexual abuse is higher in developing countries like India, Bangladesh, Pakistan, Nepal, Thailand and Philippines.

This book is based on research results published on a very serious and sensitive problem of "Beggar Girls" which is one of many evils of our society. This book is based on interviews and case studies, relevant to the field research. These interviews and case studies point out the ponder-able facts about this problem. The evil of begging is without a doubt century's old phenomenon and in every era there has been a struggle against it. It is argued that "begging bowel" is the insult of humanity and the existence of begging hands are the cancer of society. Increasing rate of population and poverty are major factors of increase in beggary. Due to increased population when people cannot acquire employment they start begging to full fill their needs in desperation. A part from that there are some mafias as well, who kidnap innocent children, turn them into disabled children and then coerce them to beg. These rackets sell such kids to each other. Therefore it is the responsibility of Government to provide people with employment and 
take actions against these mafias. Begging in a society is very much similar to crimes like theft, robbery and terrorism etc. Most of the time kidnapping rackets come to towns in outfits of beggars and kidnap children. In Pakistan beggary has shaped into a very serious problem. Business of beggary not only involve men but women and children as well. Every religion and society takes beggary as an evil deed because it kills conscience and shatters the self respect of a person.

In this book the reasons due to which the evil of beggary is rapidly becoming a cancer of our society, have also been discussed. Poverty and unemployment are at top of the list, without controlling these two problems it is different to overcome. The book also defines effects of beggary on the society and different types of beggars.

The research is based on following objectives:

1- Analysis of beggar girls' family background

2- Analysis of beggar girls' socio-economic background

3 - Finding out the reasons of beggar girls being professionals or desperate?

4- Whether or not beggar girls are satisfied with this profession, if not then study the reasons.

5- To what extent beggar girls express themselves for leaving this profession

6- The daily routine of beggar girls

7- Finding out other important problems of beggar girls

For this research chance sampling method has been used because with limited resources it is impossible to acquire information of all beggar girls of Karachi. The book also suggests some steps to overcome this issue, which if implemented could help in elimination of this evil on a very large scale. At the end of the book, conditions of beggar girls are analyzed from which knowledge of all their problems can be attained. Pictures on art paper intensify the significance of the book and subject is made more comprehendible. After reading the book it fulfils the requirement of a unique book according to the subject.

"Beggar Girls of Karachi: A Survey" Published by Centre of Excellence for Women's Studies, University of Karachi in collaboration with Higher Education Commission(HEC) Islamabad, $8^{\text {th }}$ September, 2004. 